\title{
Calcitriol, the active form of vitamin $D$, is a promising candidate for COVID-19 prophylaxis
}

Chee Keng Mok ${ }^{1,2,3}$, Yan Ling Ng${ }^{2,3}$, Bintou Ahmadou Ahidjo ${ }^{1,2,3}$, Regina Ching Hua Lee ${ }^{2,3}$ Marcus Wing Choy Loe ${ }^{2,3}$ Jing Liư ${ }^{4}$, Kai Sen Tan ${ }^{4}$, Parveen Kaur ${ }^{2,3}$, Wee Joo Chng ${ }^{5,6,7}$, John Eu-Li Wong ${ }^{5,8}$, De Yun Wang ${ }^{4}$, Erwei Hao ${ }^{11,12,13}$, Xiaotao Hou ${ }^{11,12,13}$, Yong Wah Tan ${ }^{9}$, Tze Minn Mak ${ }^{14}$, Cui Lin $^{14}$, Raymond Lin ${ }^{3,14,15}$, Paul Tambyah ${ }^{3,5,10}$ JiaGang Deng ${ }^{11,12,13}$ and Justin Jang Hann Chu ${ }^{1,2,3,9}$

${ }^{1}$ NUSMed Biosafety Level 3 Core Facility, Yong Loo Lin School of Medicine, National University of Singapore, Singapore 117599, Singapore

${ }^{2}$ Laboratory of Molecular RNA Virology and Antiviral Strategies, Department of Microbiology and Immunology, Yong Loo Lin School of Medicine, National University of Singapore, Singapore 117545, Singapore

${ }^{3}$ Infectious Disease Programme, Yong Loo Lin School of Medicine, National University of Singapore, Singapore 117597, Singapore

${ }^{4}$ Department of Otolaryngology, Yong Loo Lin School of Medicine, National University of Singapore, Singapore 119228, Singapore

${ }^{5}$ Department of Medicine, Yong Loo Lin School of Medicine, National University of Singapore, Singapore 119228, Singapore

${ }^{6}$ Cancer Science Institute of Singapore, Centre for Translational Medicine, National University of Singapore, (MD6) \#13-01G, 14 Medical Drive, Singapore 117599, Singapore

${ }^{7}$ National University Cancer Institute, National University Health System, Singapore 119228, Singapore.

${ }^{8}$ Department of Hematology - Medical Oncology, National University Cancer Institute, National University Health System, Singapore 119228, Singapore

${ }^{9}$ Collaborative and Translation Unit for HFMD, Institute of Molecular and Cell Biology, Agency for Science, Technology and Research (A*STAR), Singapore 138673, Singapore

${ }^{10}$ Division of Infectious Diseases, National University Health System, Singapore 119228, Singapore

${ }^{11}$ Guangxi Key Laboratory of Efficacy Study on Chinese Materia Medica, Guangxi University of Chinese Medicine, Nanning, Guangxi 530200, China

${ }^{12}$ Guangxi Collaborative Innovation Center for Research on Functional Ingredients of Agricultural Residues, Guangxi University of Chinese Medicine, Nanning, Guangxi, 530200, China

${ }^{13}$ China-ASEAN Joint Laboratory for International Cooperation in Traditional Medicine Research, Guangxi University of Chinese Medicine, Nanning, Guangxi, 530200, China

${ }^{14}$ National Public Health Laboratory, National Centre for Infectious Diseases, Singapore

${ }^{15}$ Department of Microbiology and Immunology, Yong Loo Lin School of Medicine, National University of Singapore, Singapore 117545 , Singapore

* To whom correspondence should be addressed: Justin Chu, Block MD4, Level 5, 5 Science Drive 2, Singapore 117597 Phone: +65-65163278 ; Email: miccih@nus.edu.sg 
Abstract: COVID-19, the disease caused by SARS-CoV-2 (1), was declared a pandemic by the World Health Organization (WHO) in March 2020 (2). While awaiting a vaccine, several antivirals are being used to manage the disease with limited success $(3,4)$. To expand this arsenal, we screened 4 compound libraries: a United States Food and Drug Administration (FDA) approved drug library, an angiotensin converting enzyme-2 (ACE2) targeted compound library, a flavonoid compound library as well as a natural product library. Of the 121 compounds identified with activity against SARS-CoV-2, 7 were shortlisted for validation. We show for the first time that the active form of Vitamin D, calcitriol, exhibits significant potent activity against SARS-CoV-2. This finding paves the way for consideration of host-directed therapies for ring prophylaxis of contacts of SARS-CoV-2 patients. 
Despite implementation of physical distancing, mask wearing, quarantine and the tireless efforts expended for contact tracing, the rapid transmissibility of SARS-CoV-2 even during the asymptomatic phase has made containment of this virus extremely difficult. The main proposed strategy to curb this pandemic is the implementation of mass vaccination programs. Once a suitable vaccine is discovered, the significant challenges associated with vaccination programs e.g. limitations in manufacturing capabilities and associated costs, are anticipated to significantly affect uptake of vaccinations globally. We therefore propose that ring prophylaxis, which had been previously proposed for influenza pandemics and involves treating close contacts of a confirmed case with an antiviral prophylaxis to further curb community spread(5), be considered as a viable strategy to reduce transmission of SARS-CoV-2.

In an effort to identify potential candidates for SARS-CoV-2 chemoprophylaxis, we performed a virusinduced cytopathic effect (CPE) based screen of several small molecule libraries in SARS-CoV-2infected Vero E6 cells (Fig. 1a). The African green monkey kidney epithelial Vero E6 cells were used for the screen as these cells are highly susceptible to coronaviruses and exhibit obvious CPE upon infection. A 57-compound natural product library and a library of 462 ACE2 targeted inhibitors (the ACE2 receptor was identified to be necessary for SARS-CoV-2 infection (6)) were used in a preinfection treatment screen to identify potential viral entry inhibitors, while a post-infection treatment screen was performed using both a 500 compound flavonoid library and a 1172 FDA-approved compound libraries in order to identify potential inhibitors targeting post-entry steps of the SARS-CoV2 replication cycle. For the pre-infection treatment screen, Vero E6 cells were treated with compounds for two hours prior to infection with SARS-CoV-2. The post-infection treatment screen on the other hand was performed by adding compounds to the Vero E6 cells 1 hour post-infection with SARSCoV-2. Compounds which showed less than $50 \%$ CPE compared to the $0.1 \% \mathrm{DMSO}$ vehicle control with SARS-CoV-2 infection were identified as hits (Tables S1- S3). Using this method, we identified 31 compounds from the pre-infection treatment screen and 90 compounds from the post-infection treatment screen with activity against SARS-CoV-2 (Table S4). As expected, our hit list included the tyrosine kinase inhibitors masitinib and imatinib mesylate (7), the antiretroviral drug lopinavir(8) and the calpain inhibitor calpeptin (9) - all compounds reported to inhibit SARS-CoV, SARS-CoV-2 or MERS-CoV. This provides the robustness and confidence of our primary screen for potential antivirals against SARS-CoV-2.

Of these primary hits, 7 compounds were selected for downstream validation (Table 1). These included 3 compounds from the pre-infection treatment screen (citicoline, pravastatin sodium and tenofovir alafenamide) and four compounds from the post-infection treatment screen (imatinib mesylate, calcitriol, dexlansoprazole, and prochlorperazine dimaleate). These compounds were selected based on level of CPE inhibition in the primary screens (Fig. 1b), known mechanism of action and existing FDA approval or Generally Recognized as Safe (GRAS) status. FDA approval was considered an important factor as pre-existing data on safety and dosage would allow expedited decisions to be made regarding the potential use of these compounds in vulnerable populations to stymie the current pandemic. Validation assays to determine changes in infectious virus titres upon treatment was carried out by testing selected hit compounds in dose-dependent assays in Vero E6 to 
confirm the primary screen observation and also in the human hepatocarcinoma $\mathrm{HuH} 7$ cell line as the latter cell line expresses high levels of the ACE2 receptor (10) and supports replication of coronaviruses (11). Cell viability assays were also carried out to ensure that reduction of SARS-CoV2 titres was not due to cytotoxic effects of the compounds on host cells. CC50, IC50 were obtained for each of the 7 compounds in Vero E6 cells (Table S5) and HuH7 cells (Table S6) and where possible selectivity index values were calculated. Pre-infection treatment of Vero E6 cells with citicoline and pravastatin sodium resulted in dose-dependent inhibition of SARS-CoV-2 (Fig. 2a \& 2b), while a nondose-dependent inhibition of SARS-CoV-2 at lower concentrations was observed with tenofovir alafenamide (Fig. 2c). These observations were however not recapitulated in $\mathrm{HuH} 7$ cell line (Fig. 2d, 2e \& 2f). Post-infection treatment with $\geq 10 \mu \mathrm{M}$ imatinib mesylate resulted in a reduction of SARS-

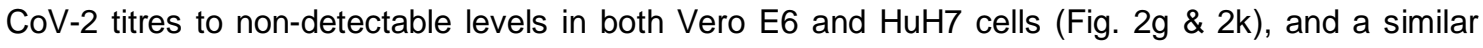
finding was observed with $\geq 10 \mu \mathrm{M}$ prochlorperazine dimaleate in $\mathrm{HuH7}$ cells (Fig. 2n). Significant reductions of at least $0.4 \log _{10}$ of SARS-CoV-2 were also noted upon treatment with $\geq 10 \mu \mathrm{M}$ dexlansoprazole (Fig. 2i, $2 \mathrm{~m}$ ) and post-infection treatment with $10 \mu \mathrm{M}$ calcitriol resulted in a $1.3 \log _{10}$ reduction of SARS-CoV-2 titre in Vero E6 cells (Fig. 2h). This finding could not be recapitulated in $\mathrm{HuH} 7$ cells (Fig. 2l) most likely because the CC50 value of calcitriol was $4.7 \mu \mathrm{M}$ in $\mathrm{HuH} 7$ cells (Table S6). Given that the HuH7 cell line is a hepatocarcinoma cell line and therefore not the first point of entry for SARS-CoV-2 in humans, we decided to test the three most promising compounds (imatinib mesylate, citicoline and calcitriol) against SARS-CoV-2 in the primary human nasal epithelial cell line (hNEC) that is a known in vivo target of SARS-CoV-2 (12) (Fig. 1a). Despite its significant activity in the continuous cell lines (Vero E6 and HuH7), in hNECs, imatinib mesylate only displayed a $0.2 \log _{10}$ reduction in viral titre (Fig. 3). Interestingly, out of the three compounds only calcitriol proved effective against SARS-CoV-2 with a reduction of $0.69 \log _{10}$ in viral titre (Fig. 3). While recent data has shown that vitamin $D$ levels are negatively associated with morbidity and mortality of COVID-19 cases (13, 14), this is the first report of a direct inhibitory effect of calcitriol on SARS-CoV-2.

Vitamin $D$ is well known to modulate host immune responses through the production of the antimicrobial peptides such as cathelicidin to promote autophagy (15). It has proven essential for host defenses against many intracellular pathogens including respiratory pathogens such as Mycobacterium tuberculosis, and has been shown to also possess anti-inflammatory properties(15). A recent study by Smith and colleagues (16) showed an association between vitamin D deficiency and SARS-CoV-2 infection and COVID-19 associated mortality. The authors speculated that vitamin D supplementation could protect against SARS-CoV-2 infection and improve patient disease outcomes(16), and our finding certainly provides credence to this hypothesis. Given that calcitriolmediated inhibition occurred upon post-treatment of Vero E6 cells and hNECs, it is likely that its mechanism of antiviral action targets the post-entry phase of viral replication.

Use of Host-directed therapies (HDTs) for prevention of infections is certainly not a new idea. Most of these therapies however rely mainly on the use of vaccines, convalescent plasma and monoclonal antibodies $(17,18)$. Small molecule HDTs have been used adjunctively for diseases such as tuberculosis (19) and have been proposed for viral pandemics (5). This strategy would overcome some of the costs and challenges associated with antiviral production, including the emergence of 
drug resistance (20). Vitamin $\mathrm{D}$ is a dietary supplement that is cheap and widely available even in low and middle income countries and is converted by the liver and kidneys into the active compound calcitriol $(21,22)$. It is however important that our findings be confirmed in vivo as well as in clinical trials in order to assess efficacy, optimal dosage, treatment duration, toxicity and safety of calcitriol. Given the high transmissibility of SARS-CoV-2 globally (23), if these findings can be replicated in clinical trials, calcitriol may certainly prove to be an effective tool in the effort to control the pandemic while waiting for an effective vaccine to be rolled out globally. At the very least, these findings certainly pave the way for consideration of host-directed therapies for ring prophylaxis of contacts of SARS-CoV-2 patients.

\section{Methods}

Cell lines and Viruses. African green monkey kidney cells (Vero E6; ATCC CRL-1586 ${ }^{\mathrm{TM}}$ ), human hepatoma cells (HuH7; Dr Priscilla Yang, Harvard Medical School, USA) and human nasal epithelial cells (hNECs; Dr Wang De Yun, National University of Singapore, Singapore) were utilised in this study. Vero E6 and HuH7 cells were cultured in Dulbecco's Modified Eagle's Medium (DMEM) (Sigma-Aldrich) supplemented with 10\% heat-inactivated fetal calf serum (FCS) and buffered with $2 \mathrm{~g}$ sodium hydrogen carbonate.

hNECs were derived from in vitro differentiation of human nasal epithelial stem/progenitor cells (hNESPCs) obtained from healthy adult donors scheduled for septal plastic surgery. Approval to collect the tissue biopsies was obtained from the National Healthcare Group Domain-Specific Board of Singapore (DSRB Ref: D/11/228) and the institutional review board of the National University of Singapore (IRB Ref: 13-509). Written consent was also obtained from the donors prior to tissue biopsies collection. At the time of biopsies collection, all subjects were free of upper respiratory tract infection and rhinitis symptoms. Once the hNESPCs were isolated and enriched using standardised protocols $(24,25)$, the hNESPCs were expanded and subjected to ALI culture in Transwells for in vitro differentiation $(24,25)$. The expanded hNESPCs were then transferred onto 12-well $0.4 \mu \mathrm{m}$ Transwell inserts (Corning). Once the cells became confluent, growth medium was discarded and $700 \mu \mathrm{l}$ of PneumaCultTM-ALI Medium with inducer supplements (STEMCELL Technologies) was added to the basal chamber to establish ALI conditions. The cells were cultured in ALI culture for 4 weeks, with media change every 2-3 days. hNECs were obtained after 3-4 weeks of differentiation were then subjected to SARS-CoV-2 infection. All cultures were maintained at $37^{\circ} \mathrm{C}, 5 \% \mathrm{CO}_{2}$.

SARS-CoV-2 (hCoV-19/Singapore/10/2020) was isolated from a nasopharyngeal swab of a COVID19 patient in February 2020. The virus isolate was validated by qRT-PCR and propagated in Vero E6 cells with no more than 3 passages prior to drug screening. The virus genome (EPI_ISL_410716) has been released to GISAID by the National Public Health Laboratory, National Centre for Infectious Diseases, Singapore and belongs to Clade O. All virus work was performed in a biosafety level 3 (BSL-3) laboratory and all protocols were approved by the BSL-3 Biosafety Committee and Institutional Biosafety Committee of the National University of Singapore.

Preparation of compound libraries for primary screen. A primary screen to identify novel compounds with potential antiviral effects against SARS-CoV-2 infection was performed on four 
different libraries, namely, a 462-compound ACE2-targeted compound library (CADD) (TargetMol), 57-compounds natural product library, 500-compound flavonoids library (TimTec) and 1172compound FDA-approved drug library (Selleckchem). Compounds were first dissolved in 100\% dimethyl sulfoxide (DMSO) to a stock concentration of $10 \mathrm{mM}$, followed by dilution to $100 \mu \mathrm{M}$ in serum-free media. Compounds were stored at $-20^{\circ} \mathrm{C}$ till further use.

Primary screen with pre-treatment using ACE2-targeted inhibitors and 57-compound natural product libraries. Vero E6 cells were seeded onto 96-well plates (Corning) at a seeding density of $1 \times 10^{4}$ cells per $100 \mu \mathrm{l}$ and incubated overnight prior to drug inhibitory assay. Pre-infection treatment drug assays were performed by treating cells with $10 \mu \mathrm{M}$ of ACE2-targeted inhibitors and the 57compound natural product libraries for $2 \mathrm{~h}$ at $37^{\circ} \mathrm{C}$. $0.1 \%$ DMSO and $100 \mu \mathrm{M}$ remdesivir were included as vehicle and positive controls, respectively. Treated cells were then washed twice with phosphate-buffered saline (PBS) prior to SARS-CoV-2 infection at a multiplicity of infection (MOI) of 1 and incubated for 4 days at $37^{\circ} \mathrm{C}, 5 \% \mathrm{CO}_{2}$, before formalin fixation, analysis and hit selection.

Primary screen with post-treatment using FDA-approved drugs and flavonoids library. Vero E6 cells were seeded onto 96-well plates (Corning) at a seeding density of $1 \times 10^{4}$ cells per $100 \mu \mathrm{l}$ and incubated overnight. Cells were infected with SARS-CoV-2 infection at a MOI of 1 for $1 \mathrm{~h}$. Final concentrations of $10 \mu \mathrm{M}$ of FDA-approved drugs and $50 \mu \mathrm{M}$ of flavonoids were added to SARS-CoV2-infected cells, respectively. $0.1 \%$ DMSO and $100 \mu \mathrm{M}$ remdesivir were included as vehicle and positive controls, respectively. Cells were then incubated for 4 days at $37^{\circ} \mathrm{C}, 5 \% \mathrm{CO}_{2}$ before formalin fixation, analysis and hit selection.

Selection of hits via analysis of cytopathic effects (CPE). For selection of hits at 4 days post infection, differences in cell viability caused by virus-induced CPE and/or compound-specific toxicity were visually analysed using light microscopy (Olympus). Hits were identified and selected based on the reduction of CPE and $>50 \%$ inhibition in duplicate wells in comparison to vehicle control.

Validation of hits. Hits identified from the primary screens were validated using cell viability and dose-dependent inhibition assays on Vero $\mathrm{E} 6$ and $\mathrm{HuH} 7$ cells. To determine the cell viability profiles of the selected compounds, Vero $\mathrm{E} 6$ and $\mathrm{HuH} 7$ cells were seeded into 96-well plates at seeding densities of $1 \times 10^{4}$ cells and $7.5 \times 10^{3}$ cells per $100 \mu$ l, respectively. Both cell lines were pre-treated with the hit compounds from the ACE2-targeted library, namely citicoline, pravastatin sodium and tenofovir alafenamide for $2 \mathrm{~h}$ at a range of concentrations $(0.01,0.1,1,10$ and $20 \mu \mathrm{M})$. Hits identified from the FDA-approved drug library, namely, imatinib mesylate, calcitriol, dexlansoprazole and prochlorperazine dimaleate were added to the cells with the same concentration range and incubated for 4 days. After incubation, the media was removed from the plates and washed once with PBS before addition of alamarBlue Cell Viability Reagent (Thermo Fisher Scientific) diluted 1:10 in media with $2 \%$ FCS. Fluorescence was detected after $2.5 \mathrm{~h}$ incubation at an excitation wavelength of 570 $\mathrm{nm}$ and an emission wavelength of $600 \mathrm{~nm}$ on an Infinite 200 Pro multiplate reader (Tecan). Data obtained from compound-treated cells and vehicle-treated cells were normalised against those obtained from untreated cells.

Validation of the primary hits was performed via dose-dependent inhibition assays. Vero E6 and $\mathrm{HuH} 7$ cells were seeded onto 96-well plates and incubated overnight prior to drug inhibitory assays. 
Pre-infection treatment with citicoline, pravastatin sodium and tenofovir alafenamide at working concentrations of $0.01,0.1,1,10,20 \mu \mathrm{M}$ was carried out for $2 \mathrm{~h}$ at $37^{\circ} \mathrm{C}$. The inhibitors were removed and washed twice with PBS prior to SARS-CoV-2 infection at an MOI of 1. For validation of imatinib mesylate, calcitriol, dexlansoprazole and prochlorperazine dimaleate, Vero $\mathrm{E} 6$ and $\mathrm{HuH} 7$ cells were infected with SARS-CoV-2 at an MOI of 1 for $1 \mathrm{~h}$ at $37^{\circ} \mathrm{C}$ and then incubated with the compounds at working concentrations. All dose-dependent inhibition assay plates were incubated for 4 days at $37^{\circ} \mathrm{C}$, $5 \% \mathrm{CO}_{2}$, prior to harvesting of viral supernatants for virus titration.

Validations of imantib mesylate, calcitrol and citicoline with primary cell line, hNEC at $10 \mu M$. hNECs were seeded in apical chambers of the Transwell inserts for 4 weeks prior to drug inhibitory assays. Pre-infection treatment with citicoline at $10 \mu \mathrm{M}$ was added to the basal chamber and carried out for $2 \mathrm{~h}$ at $37^{\circ} \mathrm{C}$. The inhibitors were removed and replaced with fresh PneumaCult ${ }^{\mathrm{TM}}$-ALI Medium (STEMCELL Technologies) prior to SARS-CoV-2 infection at an MOI of 0.1. For validation of imatinib mesylate and calcitriol, hNECs were infected with SARS-CoV-2 at a MOI of 0.1 for $1 \mathrm{~h}$ at $37^{\circ} \mathrm{C}$ before incubation with the compounds at $10 \mu \mathrm{M}$. All inhibition assay plates were incubated for 4 days at $37^{\circ} \mathrm{C}, 5 \% \mathrm{CO}_{2}$, prior to harvesting of viral supernatants for virus titration.

Plaque Assay. To determine the virus titer, viral supernatants harvested were 10 -fold serially diluted in DMEM. $200 \mu \mathrm{l}$ of each serial diluted supernatant were applied to confluent Vero E6 cells. After $1 \mathrm{~h}$ of absorption, the inoculum was removed and $500 \mu \mathrm{l}$ of $0.5 \%$ agarose overlay was added to each well and incubated for 3 days at $37^{\circ} \mathrm{C}, 5 \% \mathrm{CO}_{2}$ to facilitate plaque formation. The cells were fixed with formalin overnight and the agarose was removed before staining with crystal violet for 5 minutes. The number of plaques were counted and the virus titer of individual samples were expressed in the logarithm of plaque forming units (pfu) per $\mathrm{ml}$.

Statistical Analyses. One-way analyses of variance (ANOVA) was used to evaluate the statistical significance of data obtained. Drug-treated samples expressing statistical difference when compared to control samples were subsequently subjected to a Dunnett's post-test, with * denoting that $p<0.05$, ${ }^{* *}$ denoting that $p<0.01$ and ${ }^{* * *}$ denoting that $p<0.001$.

\section{Author contributions}

Conceived and designed the experiments: CKM, JJHC. Performed the experiments: CKM, YLN, BAA, RCHL. Analyzed the data: CKM, YLN, BAA, RCHL, MWCL, PK, PT, WJC, JEW, JJHC. Contributed reagents/materials: JL, KST, DYW, EH, XH JD, TMM, CL, RL. Wrote the paper: BAA, MWCL, YLN, $\mathrm{RCHL}, \mathrm{PK}, \mathrm{CKM}, \mathrm{YWT}$, JJHC. All the authors read the manuscript and approved it before submission

\section{Acknowledgments}

We are grateful to the Yong Loo Lin School of Medicine BSL-3 Core Facility for their support with this work. This work was supported through the following funding mechanisms:

NUHSRO/2020/066/NUSMedCovid/01/BSL3 Covid Research Work; NUHSRO/2020/050/RO5+5/NUHS-COVID/4; Ministry of Education, Singapore, MOE Tier

2, MOE2017-T2-2-014; Singapore NMRC Centre Grant Program - Diabetes, Tuberculosis and Neuroscience (CGAug16M009); MOH-COVID19RF2-0001; Sino-Singapore Cooperation for 
Evaluating the Effectiveness and Application of Guangxi Zhuang/Yao Medicines Against COVID-19 (No. GUIKE AB20036001)

\section{References}

1. Coronaviridae Study Group of the International Committee on Taxonomy of V. The species Severe acute respiratory syndrome-related coronavirus: classifying 2019-nCoV and naming it SARS-CoV-2. Nat Microbiol. 2020;5(4):536-44.

2. WHO. Rolling updates on coronavirus disease (COVID-19). https://www.who.int/emergencies/diseases/novel-coronavirus-2019/events-as-they-happen.

Accessed 8 June 2020.

3. Fajgenbaum DC, Khor JS, Gorzewski A, Tamakloe MA, Powers V, Kakkis JJ, et al. Treatments Administered to the First 9152 Reported Cases of COVID-19: A Systematic Review. Infect Dis Ther. 2020.

4. Ahidjo BA, Loe M, Ng YL, Mok CK, and Chu JJH. Current Perspective of Antiviral Strategies against COVID-19. ACS Infect Dis. 2020.

5. Balicer RD, Huerta M, and Grotto I. Tackling the next influenza pandemic. BMJ. 2004;328(7453):1391-2.

6. Zhou P, Yang XL, Wang XG, Hu B, Zhang L, Zhang W, et al. A pneumonia outbreak associated with a new coronavirus of probable bat origin. Nature. 2020;579(7798):270-3.

7. Dyall J, Coleman CM, Hart BJ, Venkataraman T, Holbrook MR, Kindrachuk J, et al. Repurposing of clinically developed drugs for treatment of Middle East respiratory syndrome coronavirus infection. Antimicrob Agents Chemother. 2014;58(8):4885-93.

8. Yan D, Liu XY, Zhu YN, Huang L, Dan BT, Zhang GJ, et al. Factors associated with prolonged viral shedding and impact of Lopinavir/Ritonavir treatment in hospitalised noncritically ill patients with SARS-CoV-2 infection. Eur Respir J. 2020.

9. Barnard DL, Hubbard VD, Burton J, Smee DF, Morrey JD, Otto MJ, et al. Inhibition of severe acute respiratory syndrome-associated coronavirus (SARSCoV) by calpain inhibitors and beta-D-N4-hydroxycytidine. Antivir Chem Chemother. 2004;15(1):15-22.

10. Nie Y, Wang P, Shi X, Wang G, Chen J, Zheng A, et al. Highly infectious SARS-CoV pseudotyped virus reveals the cell tropism and its correlation with receptor expression. Biochem Biophys Res Commun. 2004;321(4):994-1000.

11. Freymuth F, Vabret A, Rozenberg F, Dina J, Petitjean J, Gouarin S, et al. Replication of respiratory viruses, particularly influenza virus, rhinovirus, and coronavirus in $\mathrm{HuH} 7$ hepatocarcinoma cell line. J Med Virol. 2005;77(2):295-301.

12. Sungnak W, Huang N, Becavin C, Berg M, Queen R, Litvinukova M, et al. SARS-CoV-2 entry factors are highly expressed in nasal epithelial cells together with innate immune genes. Nat Med. 2020;26(5):681-7.

13. Ilie PC, Stefanescu $S$, and Smith $L$. The role of vitamin $D$ in the prevention of coronavirus disease 2019 infection and mortality. Aging Clin Exp Res. 2020:1-4. 
14. Grant WB, Lahore H, McDonnell SL, Baggerly CA, French CB, Aliano JL, et al. Evidence that Vitamin D Supplementation Could Reduce Risk of Influenza and COVID-19 Infections and Deaths. Nutrients. 2020;12(4).

15. Gombart AF. The vitamin D-antimicrobial peptide pathway and its role in protection against infection. Future Microbiol. 2009;4(9):1151-65.

16. Ilie PC, Stefanescu S, and Smith L. The role of vitamin $D$ in the prevention of coronavirus disease 2019 infection and mortality. Aging Clin Exp Res. 2020.

17. ClinicalTrials.gov. https://clinicaltrials.gov/ct2/results/browse?cond=COVID$19 \&$ term $=\&$ ntry $=\&$ state $=\& c i t y=\& d i s t=\&$ Search $=$ Search\&brwse=cond alpha all\&type=Intr. Accessed 21 April 2020.

18. Tu YF, Chien CS, Yarmishyn AA, Lin YY, Luo YH, Lin YT, et al. A Review of SARS-CoV-2 and the Ongoing Clinical Trials. Int J Mol Sci. 2020;21.

19. WHO. Geneva: World Health Organisation; 2020.

20. van Genugten ML, Heijnen ML, and Jager JC. Pandemic influenza and healthcare demand in the Netherlands: scenario analysis. Emerg Infect Dis. 2003;9(5):531-8.

21. Nair S. Vitamin d deficiency and liver disease. Gastroenterology \& hepatology. 2010;6(8):4913.

22. Rodriguez M, Munoz-Castaneda JR, and Almaden Y. Therapeutic use of calcitriol. Current vascular pharmacology. 2014;12(2):294-9.

23. Wei WE, Li Z, Chiew CJ, Yong SE, Toh MP, and Lee VJ. Presymptomatic Transmission of SARS-CoV-2 - Singapore, January 23-March 16, 2020. MMWR Morb Mortal Wkly Rep. 2020;69(14):411-5.

24. Yan Y, Tan KS, Li C, Tran T, Chao SS, Sugrue RJ, et al. Human nasal epithelial cells derived from multiple subjects exhibit differential responses to H3N2 influenza virus infection in vitro. $J$ Allergy Clin Immunol. 2016;138(1):276-81 e15.

25. Zhao X, Yu F, Li C, Li Y, Chao SS, Loh WS, et al. The use of nasal epithelial stem/progenitor cells to produce functioning ciliated cells in vitro. Am J Rhinol Allergy. 2012;26(5):345-50. 
Figure 1: Schematic overview of the anti-SARS-CoV-2 drug screening procedure. (a) ACE2 targeted inhibitors and compounds from the natural product library were applied prior to infection with SARS-CoV-2 (pre-infection treatment) while compounds from the FDA-approved library and the flavonoid library were applied post infection (post- infection treatment). Out of 2191 compounds tested, 121 displayed viral CPE reductions and 7 were selected for further validations using Vero E6, $\mathrm{HuH7}$, and hNEC cell lines. (b) Uninfected cells, infected cells treated with $0.1 \%$ DMSO and infected cells treated with remdesivir were included as controls.

Figure 2: Validation of primary hits. For validating compounds with activity pre-infection, Vero E6 cells were first pre-treated with increasing concentrations of (a) citicoline, (b) pravastatin sodium and (c) tenofovir alafenamide prior to infection with SARS-CoV-2. Similarly, Huh7 cells were also pretreated with (d) citicoline, (e) pravastatin sodium and (f) tenofovir alafenamid and subsequently infected with SARS-CoV-2. For post-infection treatment validation, Vero E6 cells were infected with SARS-CoV-2 and treated with increasing concentrations of (g) imatinib mesylate, (h) calcitriol, (i) dexlansoprazole and (j) prochlorperazine dimaleate. Similarly, HuH7 cells were also infected and treated with a range of concentrations of $(k)$ imatinib mesylate, $(\mathrm{l})$ calcitriol, $(\mathrm{m})$ dexlansoprazole and (n) prochlorperazine dimaleate. The primary and secondary exes correspond to the viral titre and relative cell viability, and the dashed line represents the $\mathrm{CC}_{50}$ cut-off for cell viability. ${ }^{*}$ denotes $p<$ $0.05,{ }^{* *} p<0.01$ and ${ }^{* * *} p<0.001$. Error bars represent the standard deviation observed from the means of triplicates performed for both cell viability and dose-dependent inhibition studies.

Figure 3: Validation of primary hits in hNECs. hNECs were either pre-treated with $10 \mu \mathrm{M}$ citicoline prior to SARS-CoV-2 infection or treated following SARS-CoV-2 infection with $10 \mu \mathrm{M}$ imatinib mesylate and $10 \mu \mathrm{M}$ calcitriol. ${ }^{* *}$ denotes that $p<0.01$. Error bars represent the standard deviation observed from the means of triplicates performed for dose-dependent inhibition studies.

Table 1: Summary of compounds identified from the primary screen that exhibit potential antiviral effects against SARS-CoV-2 infection. 
Pre-treatment Post-treatment

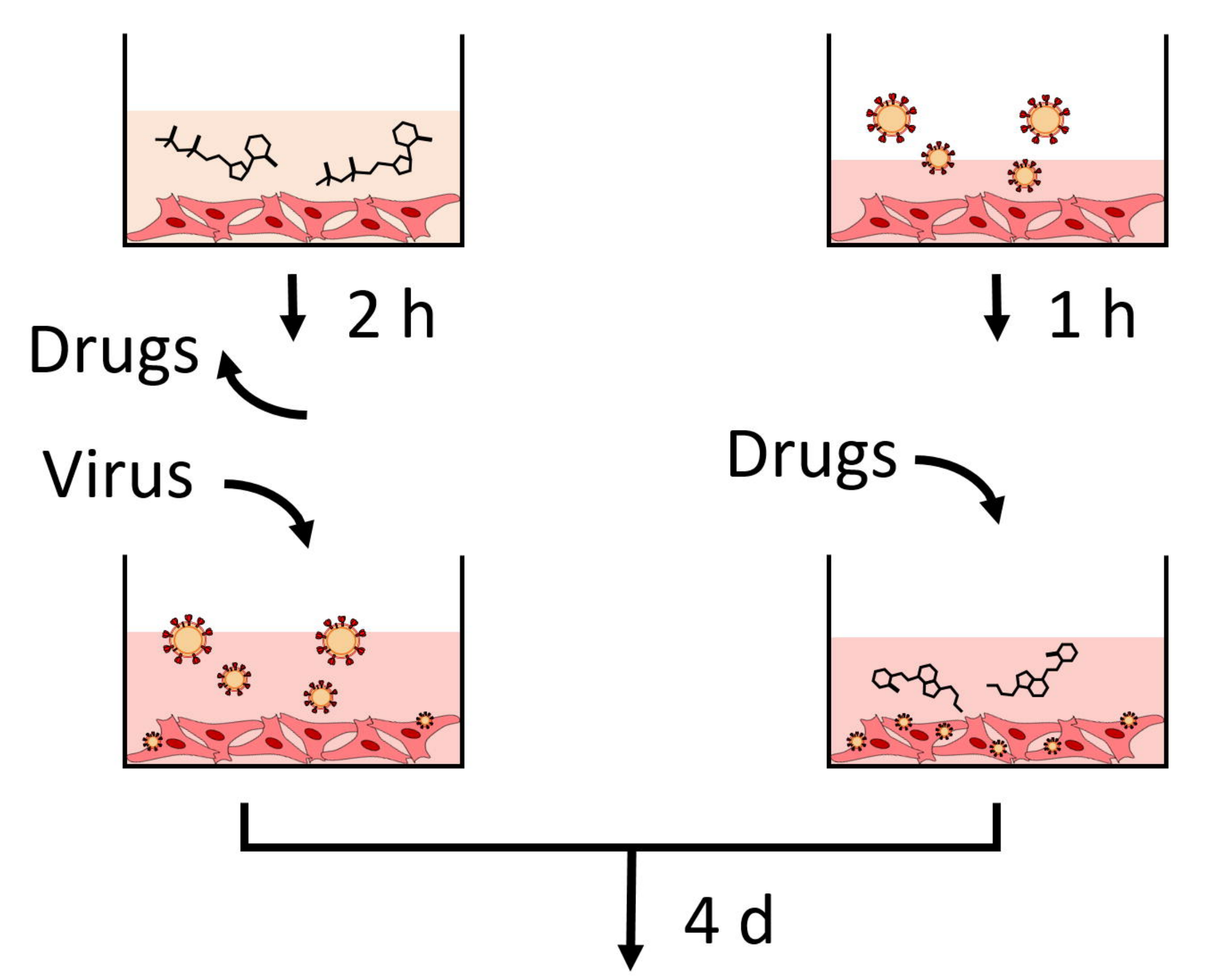

Microscopy screening

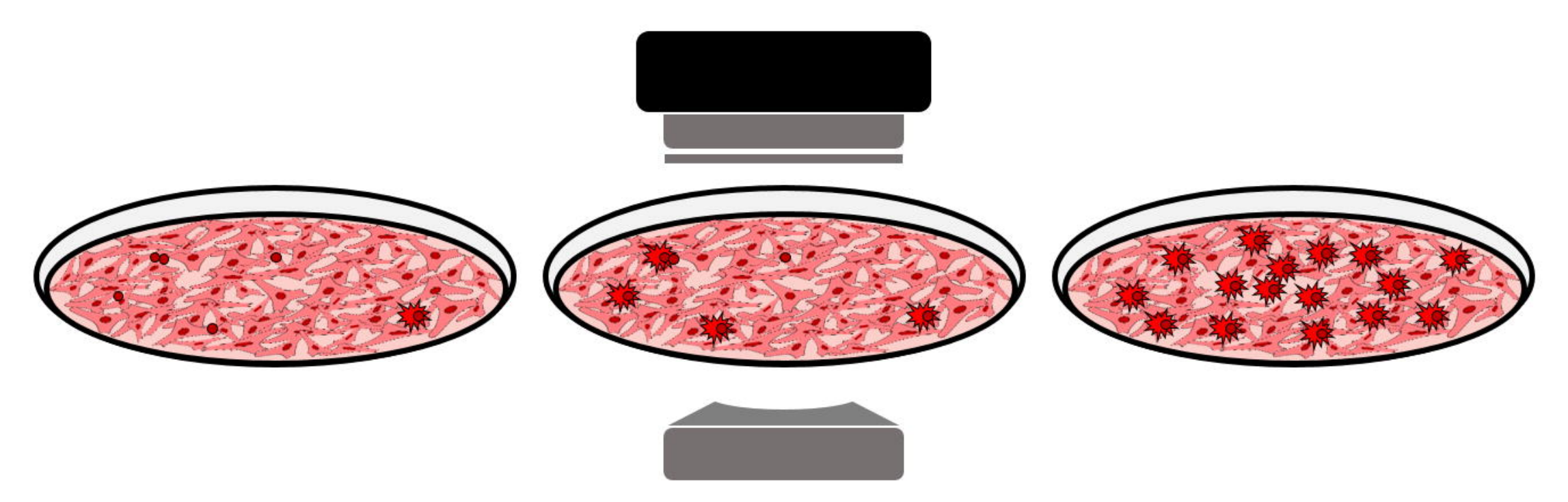

$\downarrow$ Hits selection

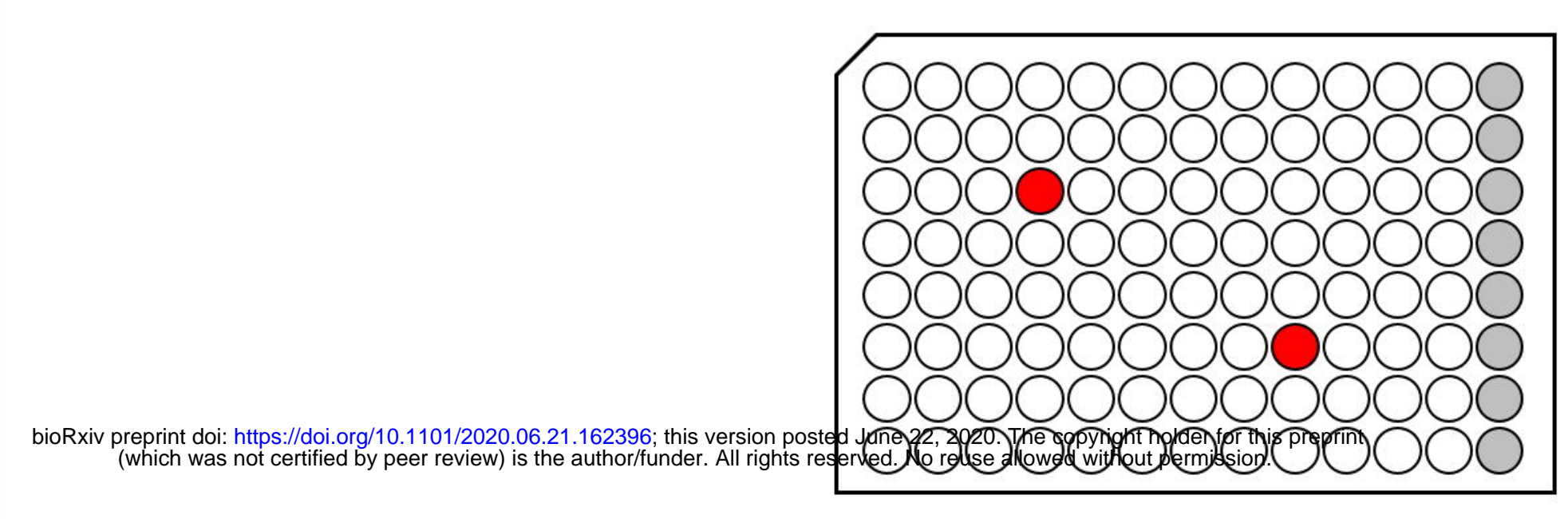

$\downarrow$ Hits validation

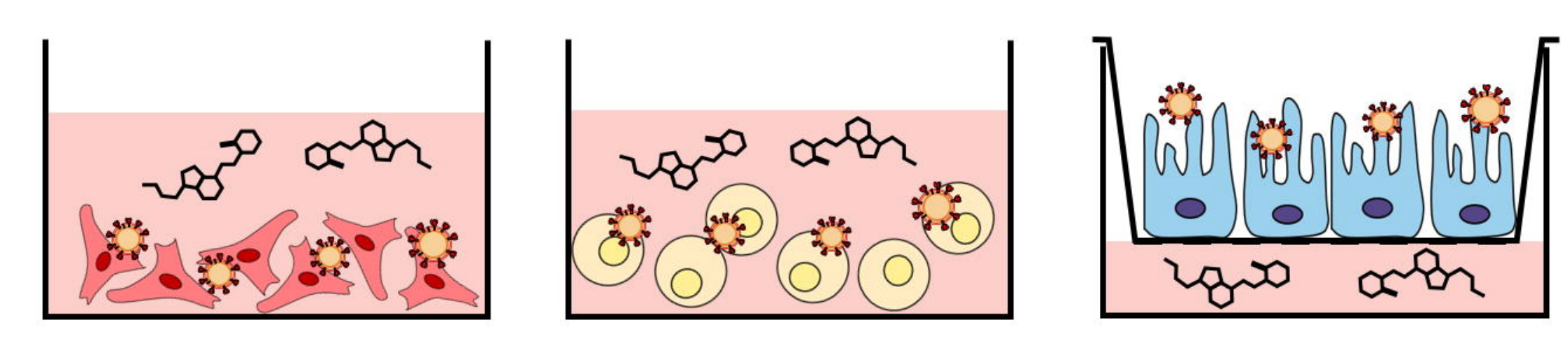

Vero E6

Huh7

hNEC

$\downarrow$ Results analysis

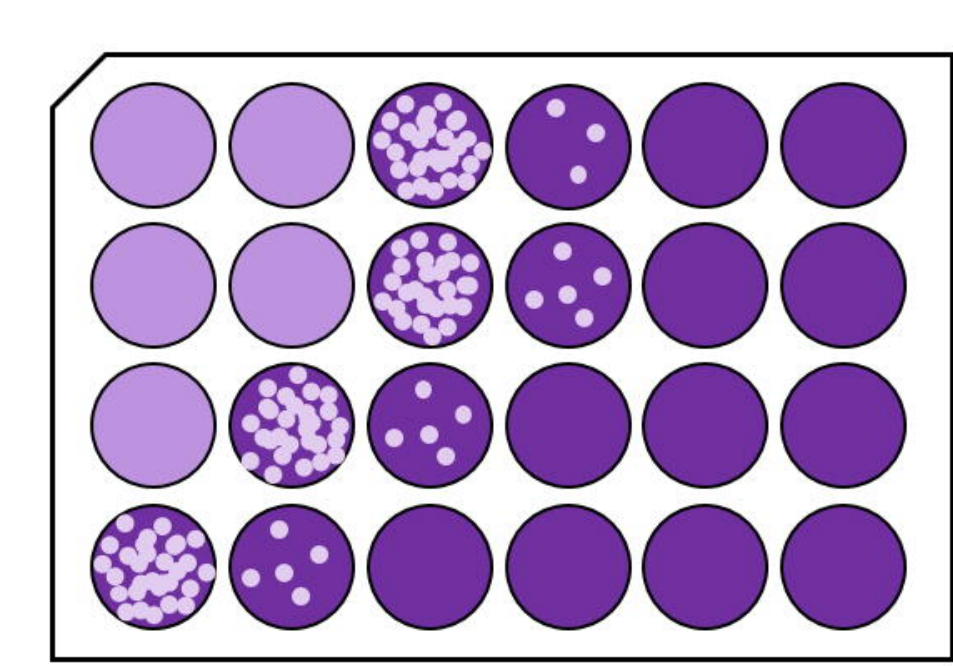

Virus titration

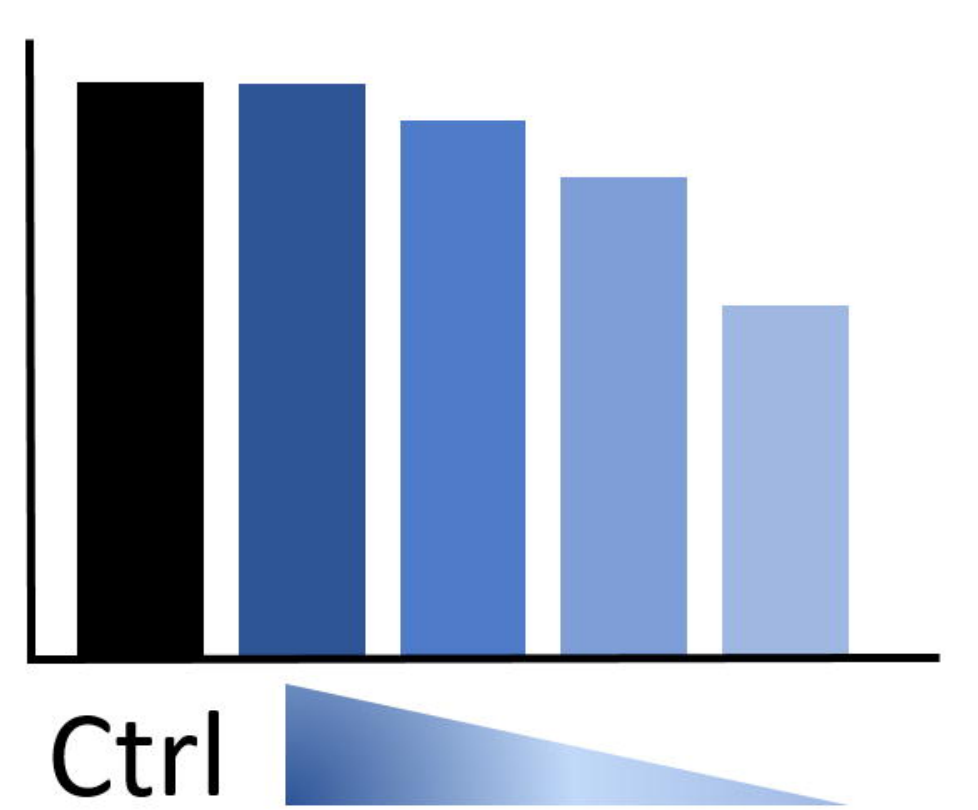

Uninfected

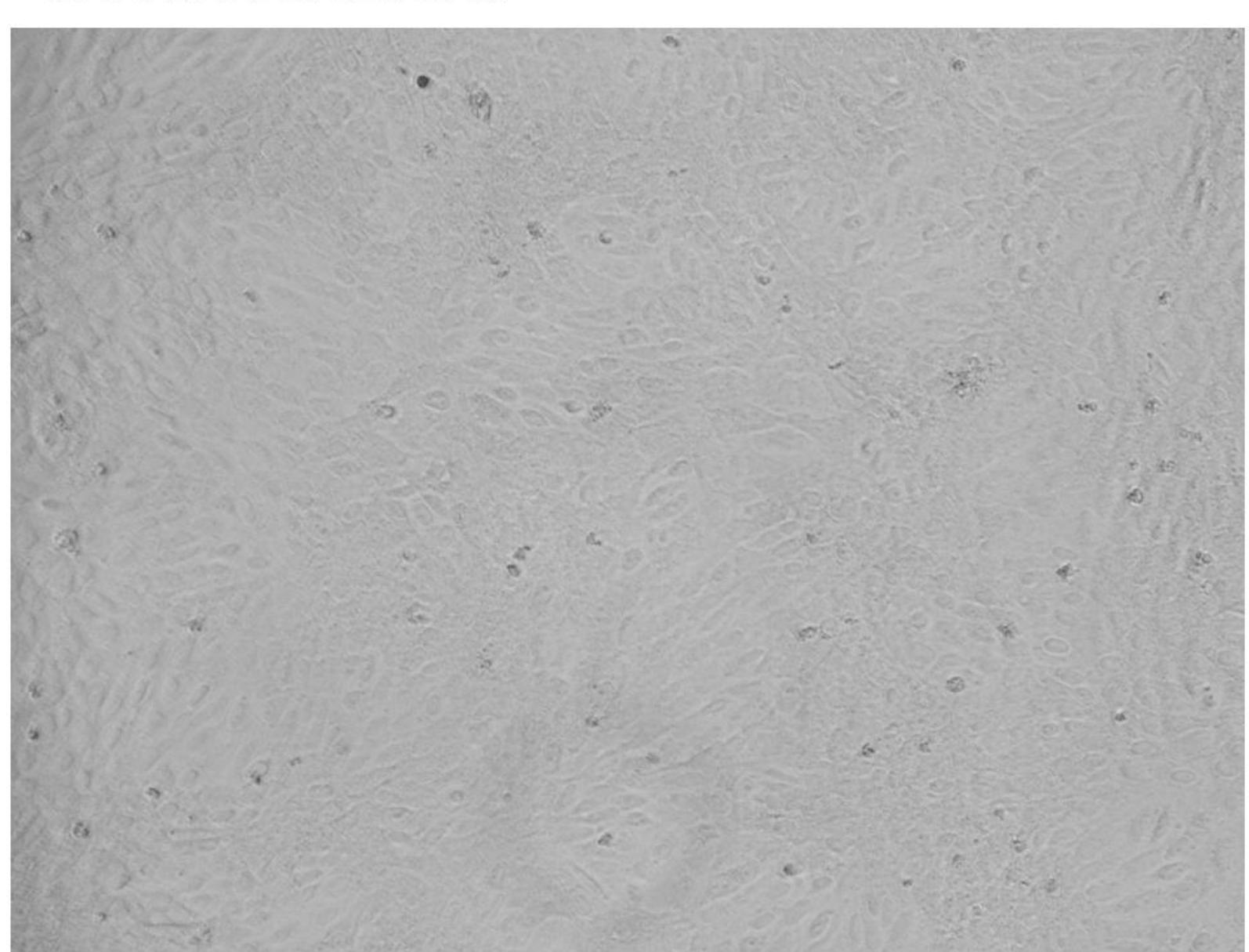

Remdesivir

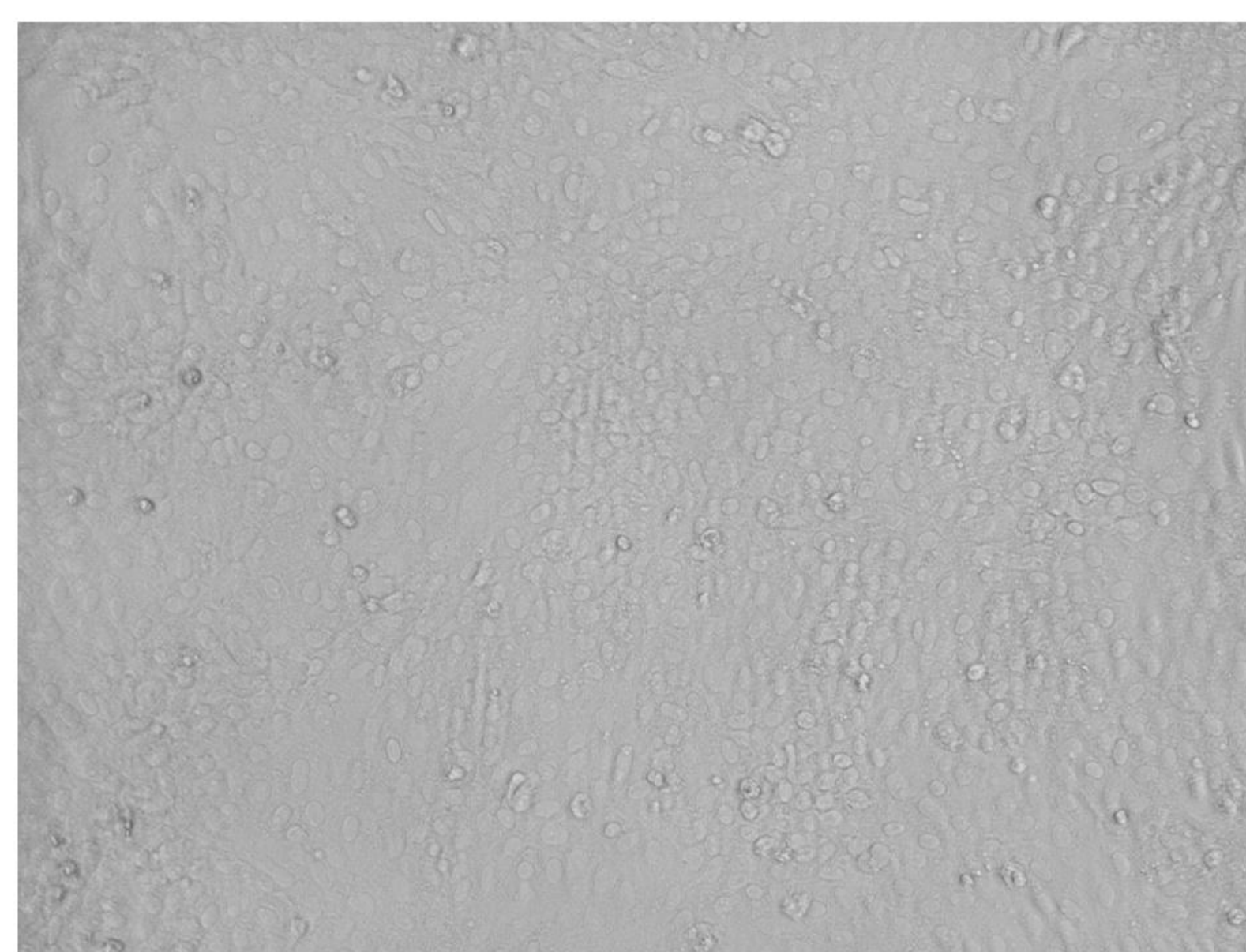

Pravastatin Sodium

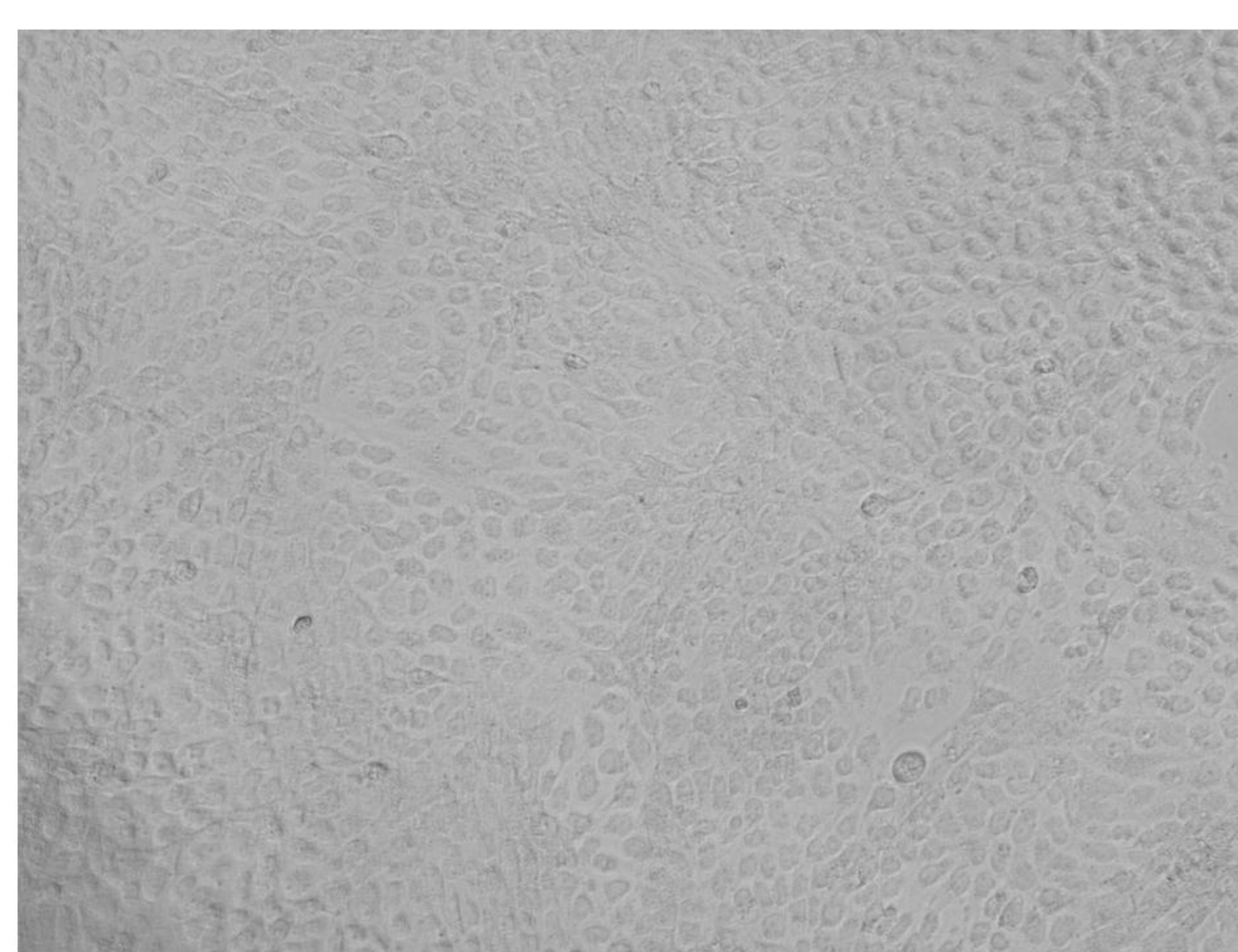

Imatinib Mesylate

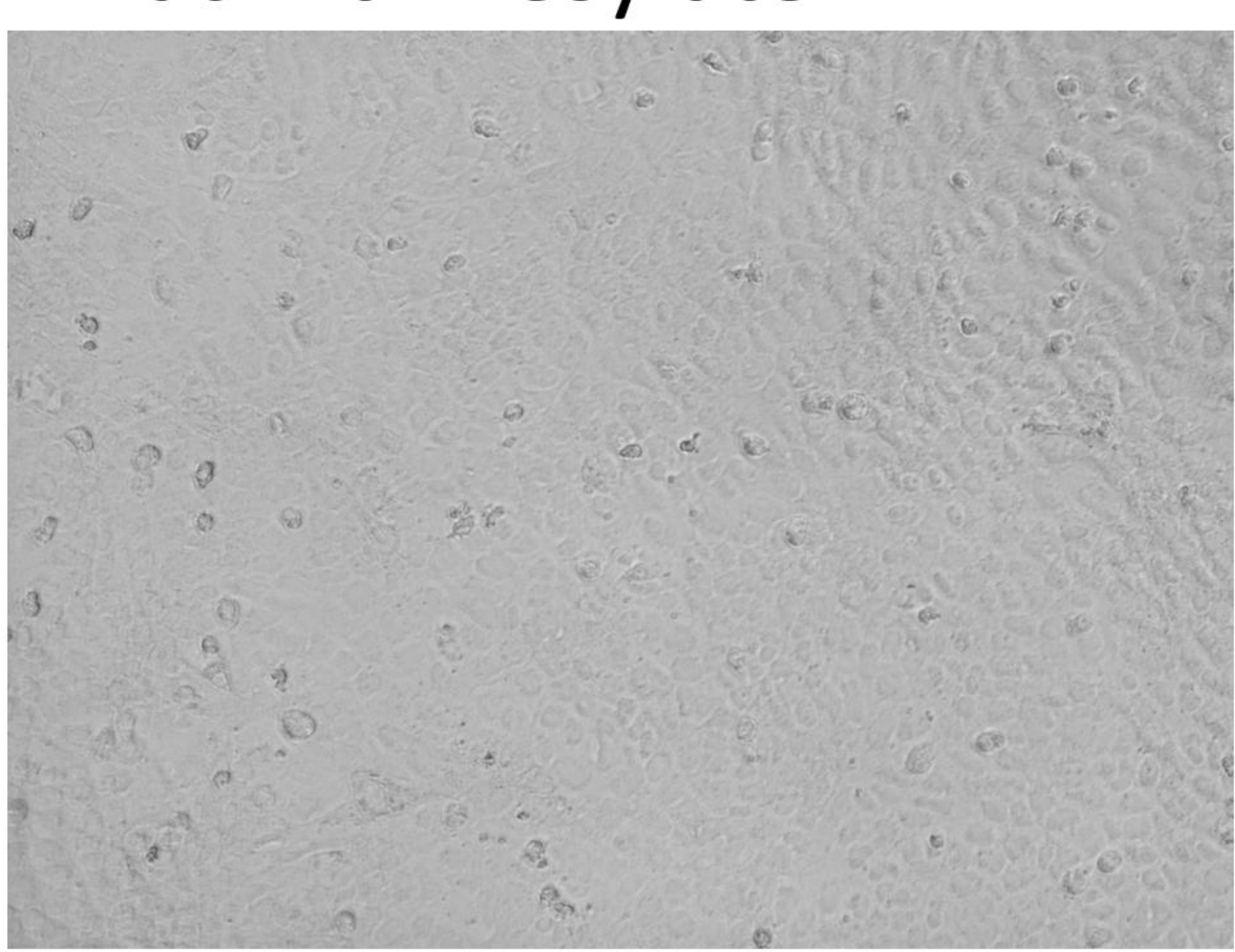

Dexlansoprazole

\section{$0.1 \%$ DMSO}

\section{Citicoline}

\section{Tenofovir Alafenamide}

\section{Calcitriol}

Prochlorperazine Dimaleate 


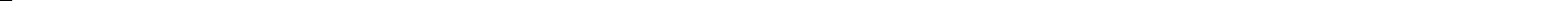




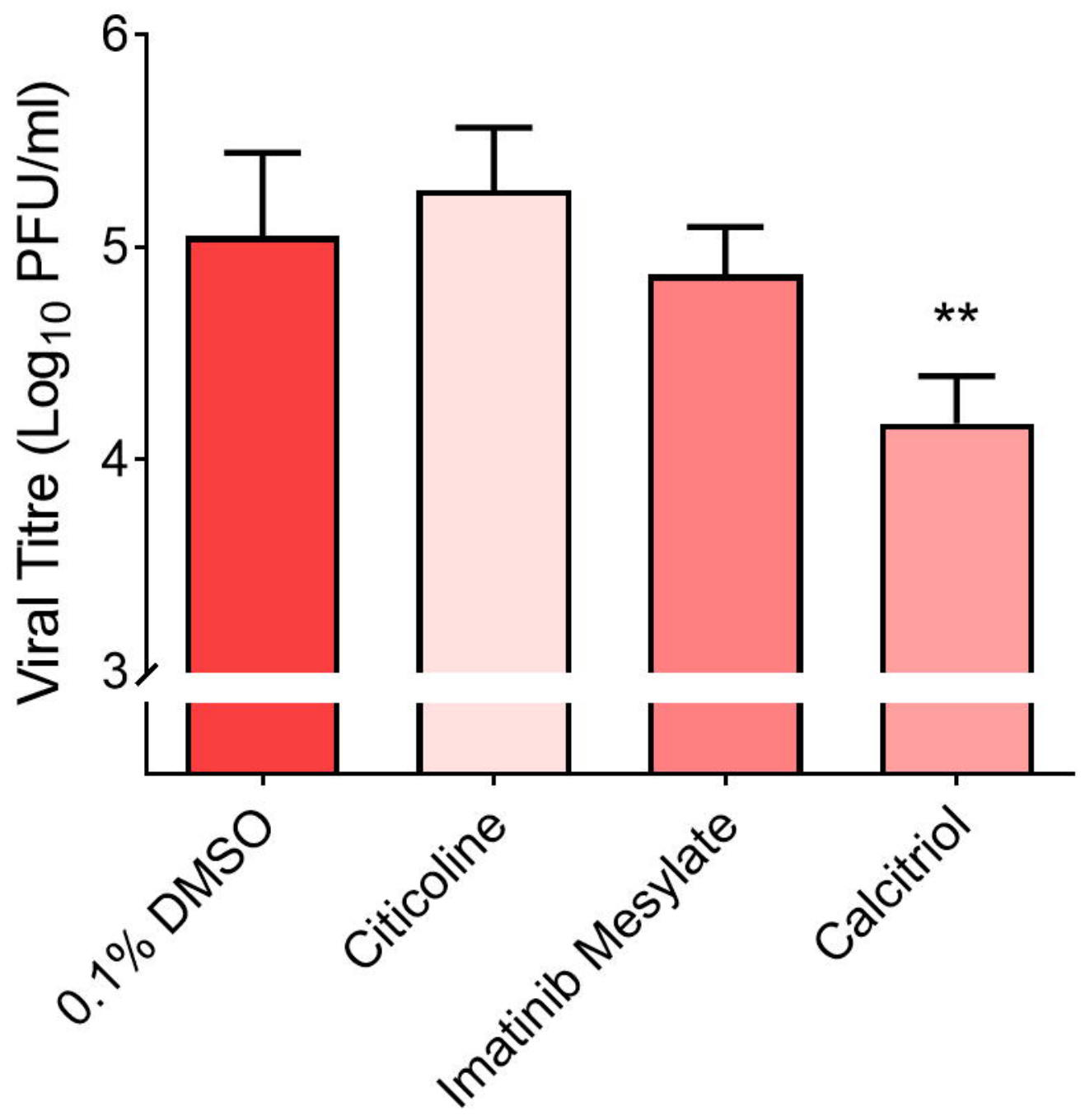




\begin{tabular}{|c|c|c|c|c|c|}
\hline Compound & Chemical Structure & $\begin{array}{c}\text { Pharmaceutical } \\
\text { Class }\end{array}$ & Known Mechanism & Indication & $\begin{array}{c}\text { FDA- } \\
\text { approved }\end{array}$ \\
\hline Citicoline & & Others & $\begin{array}{l}\text { Intermediate in the } \\
\text { synthesis of } \\
\text { phospatidylcholine }\end{array}$ & $\begin{array}{l}\text { Proposed for use in traumatic brain } \\
\text { injuries, stroke and vascular } \\
\text { dementia due to potential } \\
\text { neuroprotective effects }\end{array}$ & No \\
\hline $\begin{array}{l}\text { Pravastatin } \\
\text { Sodium }\end{array}$ & & $\begin{array}{l}\text { Lipid, sterol } \\
\text { metabolism } \\
\text { inhibitor }\end{array}$ & $\begin{array}{l}\text { Inhibits HMG-CoA } \\
\text { reductase, thus inhibiting } \\
\text { the synthesis of } \\
\text { cholesterol }\end{array}$ & $\begin{array}{l}\text { Prevention of cardiovascular disease } \\
\text { and treatment of } \\
\text { hypercholesterolemia }\end{array}$ & Yes \\
\hline $\begin{array}{l}\text { Tenofovir } \\
\text { Alafenamide }\end{array}$ & & Antiviral & $\begin{array}{l}\text { Nucleoside inhibitor of } \\
\text { viral reverse } \\
\text { transcriptase }\end{array}$ & $\begin{array}{l}\text { Prodrug form of tenofovir, used for } \\
\text { treatment of HIV and chronic } \\
\text { Hepatitis B infections }\end{array}$ & Yes \\
\hline Imatinib Mesylate & & $\begin{array}{l}\text { Signalling kinase } \\
\text { inhibitor }\end{array}$ & $\begin{array}{l}\text { Inhibits Bcr-Abl tyrosine } \\
\text { kinase }\end{array}$ & $\begin{array}{l}\text { Treatment of chronic myelogenous } \\
\text { leukemia, gastrointestinal stromal } \\
\text { tumors and various other cancers }\end{array}$ & Yes \\
\hline Calcitriol & & Others & $\begin{array}{l}\text { Active metabolite of } \\
\text { vitamin } D_{3}\end{array}$ & $\begin{array}{l}\text { Treatment of secondary } \\
\text { hyperparathyroidism and metabolic } \\
\text { bone disease, hypocalcemia, } \\
\text { osteoporosis }\end{array}$ & Yes \\
\hline Dexlansoprazole & & $\begin{array}{l}\text { Proton pump } \\
\text { inhibitor }\end{array}$ & $\begin{array}{l}\text { Inhibits } \mathrm{H}^{+} / \mathrm{K}^{+} \mathrm{ATPase} \\
\text { resulting in decreased } \\
\text { secretion of } \mathrm{HCl} \text { into the } \\
\text { gastric lumen }\end{array}$ & $\begin{array}{l}\text { Treatment and management of } \\
\text { gastroesophageal reflux, erosive } \\
\text { esophagitis }\end{array}$ & Yes \\
\hline $\begin{array}{l}\text { Prochlorperazine } \\
\text { Dimaleate }\end{array}$ & & $\begin{array}{l}\text { Neurotransmitter } \\
\text { inhibitor }\end{array}$ & $\begin{array}{l}\text { Blocks } D_{2} \text { dopamine } \\
\text { receptors in the brain }\end{array}$ & $\begin{array}{l}\text { Treatment of severe nausea and } \\
\text { vomiting, as well as short-term } \\
\text { management of anxiety and } \\
\text { schizophrenia }\end{array}$ & Yes \\
\hline
\end{tabular}

